\title{
Diary Completion Instructions
}

\author{
Werner J. Becker ${ }^{1}$ and Irene Worthington ${ }^{2}$ on behalf of the Canadian Headache \\ Society Acute Migraine Treatment Guideline Development Group
}

Can J Neurol Sci. 2013; 40: Suppl. 3 - S79-S80

\section{Headache severity}

Please record you greatest headache severity during each of the segments of the day: morning, afternoon, and evening / night. Use the scale provided just below the boxes. If you find it too demanding to fill out the diary three times a day, you could leave it in your bedroom, and fill in the diary at the end of the day while your experience of that day is still fresh in your mind.

\section{Acute medications}

These are medications which you take to treat individual headache attacks. Once you have placed the names of your acute medications in the left-hand column, simply place in the appropriate box the number of tablets you took that day for each medication. Record also the "overall" relief you received from each medication that you took that day. A scale is provided just below the acute medication section for your use.

\section{Preventive medications}

Place the names of each of your preventive medications in the left hand column, along with your tablet size in milligrams. Then each day record how many tablets you took of each medication. There is no "Overall relief" section here, as preventive medications are taken to reduce migraine frequency, not to provide short term relief.

\section{Menstrual periods}

Place an " $x$ " on each day that you experience menstrual bleeding. This will help to show whether your headaches are triggered by menstruation, and this in turn may help determine which treatments are best for you.

\section{Disability for the day}

Here you can indicate how much your migraine impacted your activities that day. Use a number from the scale provided.

\section{Triggers}

Migraine triggers are things that you experience which seem to bring on a headache at least some of the time. They include things like stress, weather changes, certain foods, and many others.

See following page for Diary

\footnotetext{
From the ${ }^{1}$ University of Calgary and the Hotchkiss Brain Institute, Calgary, Alberta; ${ }^{2}$ Sunnybrook Health Sciences Centre, Toronto, Ontario, Canada

Received June 9, 2013. Final Revisions Submitted June 22, 2013.
}

Correspondence to: W.J. Becker, Division of Neurology, 12th Floor, Foothills Hospital, 1403 29th St NW, Calgary, Alberta, T2N 2T9, Canada. 

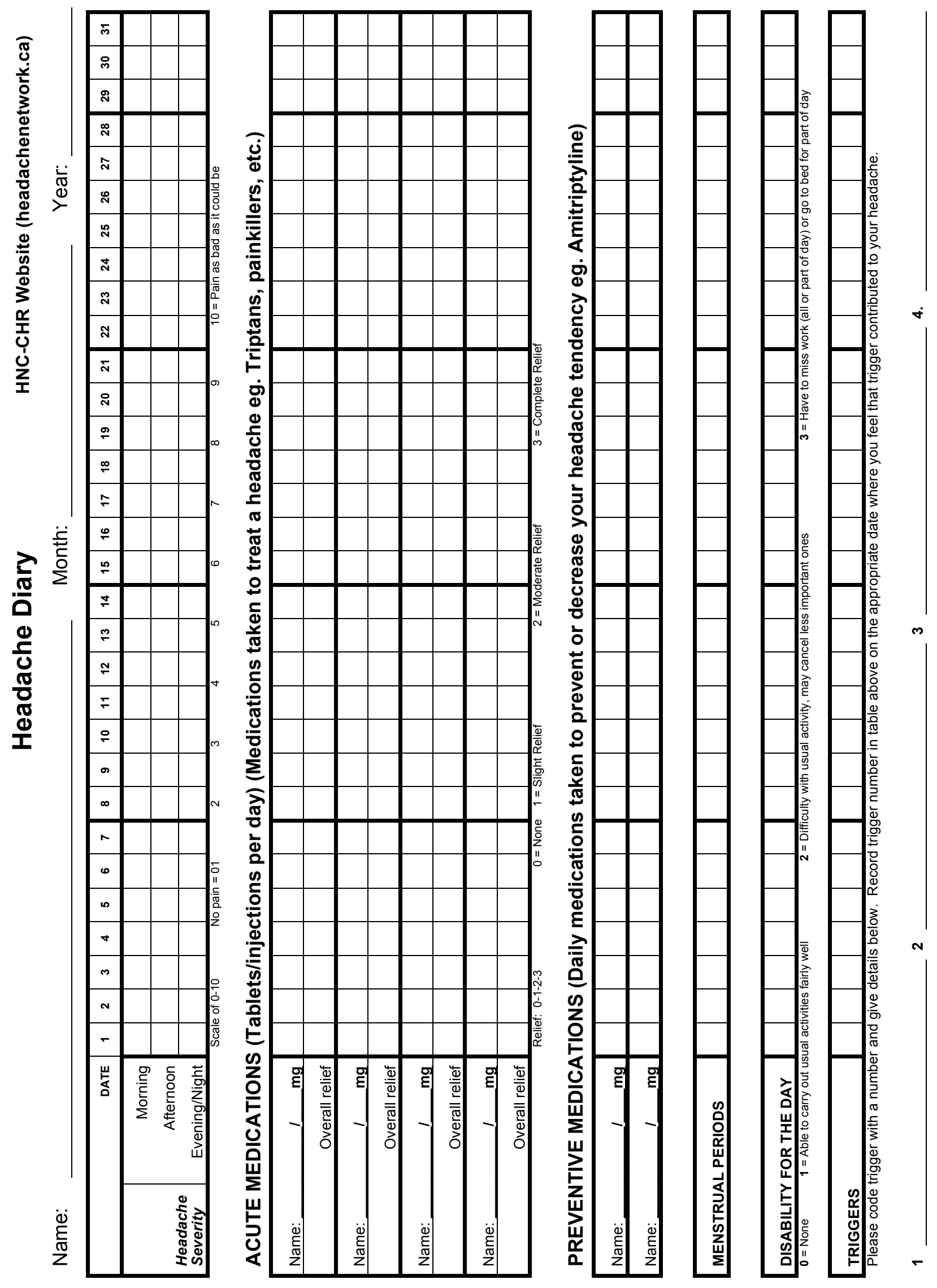